\title{
EXPRESSION THROUGH GROWING FOOD AND COOKING: THE CRAFT CONSUMPTION OF FOOD
}

Luka ZEVNIK

Faculty of Social Sciences, Liubliana

UDK: 316.728:641.5

Pregledni rad

Primlieno: 20. 10. 2011.

This article applies Campbell's (2005) theory of craft consumption to contemporary food culture. It argues that, besides cooking and the preparation of food, certain modes of domestic food growing can also be regarded as the craft consumption of food. At its core it tries to identify the conditions and possible motives for both modes of the craft consumption of food that can shed light on social, symbolic, expressive and economic specifics of the new forms of food practices and help describe how they differ from their traditional patterns. Last but not least, the article argues that insomuch as craft activities are by definition always leisure activities the application of the notion of the craft consumption to food culture can also provide us with a better understanding of cooking and home food growing as leisure activities.

Keywords: food culture, craft consumer, craft consumption of food, (self)-expression, cooking, domestic food growing, leisure

Luka Zevnik, Department and Chair of Cultural Studies, Centre for Cultural and Religious Studies, University of Liubljana, Faculty of Social Sciences, Kardeljeva ploščad 5, 1000 Ljubliana, Slovenia.

E-mail: Luka.Zevnik@fdv.uni-li.si

\section{INTRODUCTION}

People have always wanted to eat well and some form of gastronomic hedonism has always existed (especially amongst the ruling classes). ${ }^{1}$ Yet in the history of human culture, not only eating but also cooking itself or even growing food have been considered a pleasure to an extent seen in postmodern soci- 
DRUŠ. ISTRAŽ. ZAGREB GOD. 21 (2012), BR. $3(117)$

STR. 753-769

ZEVNIK, L.: EXPRESSION THROUGH... ety: 'Cooking's gotta be a laugh ... It's gotta be simple, it's gotta be tasty, it's gotta be fun!' claims Jamie Oliver, one of today's most popular celebrity chefs.

Similarly, domestic food growing is also acquiring new social, symbolic and expressive dimensions in contemporary society. In spite of the hyper-productive food industry, some people are 'attacking their front lawns' and planting crops right in front of their houses. This is not because they would otherwise starve like their ancestors did, but obviously, due to some other motives and reasons, which we would also like to examine here. In postmodernity, food culture and food practices are extending towards ever new horizons of human existence. Since these important transformations of postmodern food culture correspond to the new type of consumer that Collin Campbell (2005) calls a 'craft consumer', the principal aim of this article is to apply the extended notion of the craft consumer to the field of contemporary Western food culture. As a consequence, the article will try to illuminate the material, economic, cultural, political and temporal conditions for the craft consumption of food and seek to identify possible individual and collective reasons and motives for it, that can, in turn, produce new understandings of how people relate to and make sense of food and cooking. Such an undertaking will enable us to acknowledge social, symbolic, expressive and economic specifics of the new forms of food practices and describe how they differ from their traditional patterns. Insomuch as craft activities are by definition always leisure activities, the article will also explore the relation between cooking as leisure and cooking as craft consumption. In this sense, it will argue that the application of the notion of the craft consumption to food culture can help us better understand cooking and home food growing as leisure activities.

To support our arguments, we use two main strategies. We conduct discourse analysis of selected popular media content and books representing contemporary food culture and combine it with empirical insights of other researchers of contemporary food culture like Bourdieu (1984), Lupton (1996) and Ashley et al. (2004). Insofar as there are two main modes of craft consumption of food, the discourse analysis will focus on popular media content and books that, in our view, represent the most widespread examples of these two modes of craft consumption. We will conduct discourse analysis of Jamie Oliver's shows because in the recent years they have been one of the most popular and widespread TV cookery shows, with its star being the first celebrity TV chef that has made it in multiple countries (see Ashley et al., 2004). What was perhaps even more crucial for our selection was the fact that one of the seasons of Jamie Oliver's shows is the first and the only 
DRUŠ. ISTRAŽ. ZAGREB GOD. 21 (2012), BR. $3(117)$

STR. $753-769$

ZEVNIK, L.: EXPRESSION THROUGH... popular and widespread TV program so far that clearly represents home food growing as craft consumption. In addition to the more entertainment oriented twist of Jamie Oliver's shows, we also conduct discourse analysis of more instructional content on home food growing that can be mostly found in the form of DIY (do-it-yourself) books. Out of numerous books covering the topic, we have selected Flores' book Food not Lawns and Haegs' book Attack on the Front Lawn, ${ }^{2}$ mostly because they are exceptional in terms of not only providing instructions on how to grow food, but also convey a clear political and lifestyle statement about home food growing. Furthermore, they are also one of the most popular books in their field. We believe that our discourse analysis is relevant because the content that will be analysed clearly represents the lifestyles of people who already engage in new patterns of food culture. Moreover, such media content provides detailed instructions on how to relate to food and cooking in different new ways. As we shall see, there is already evidence indicating that such content inspires and encourages people to change their culinary patterns.

\section{THE CRAFT CONSUMER}

The term craft consumer was proposed by Campbell (2005, 24) because he believes the existing understanding of consumer types does not 'appear to correspond all that closely to the picture of consumer behaviour that research reveals'. Campbell $(2005,27)$ claims that:

\begin{abstract}
much of the consumption that individuals undertake in contemporary western societies should be conceived of as craft activity; that is, as activity in which individuals not merely exercise control over the consumption process, but also bring skill, knowledge, judgment, love and passion to their consuming in much the same way that it has always been assumed that traditional craftsmen and craftswomen approach their work.
\end{abstract}

Although, according to Campbell, craft consumers do not have an 'overwhelming concern with their image, lifestyle and identity' and thus consume commodities 'principally out of desire to engage in creative acts of self-expression' (Campbell, 2005, 24), this 'is not to deny that consumption activity may relate to issues of identity' (Campbell, 2005, 40). For Campbell $(2005,39)$, craft consumption 'does not merely exist in contemporary consumer society, but is actually flourishing and can be seen as part of the widespread aestheticization of everyday life and the fact that consumption imperatives, rather than production ones, now tend to mould contemporary cul- 
DRUŠ. ISTRAŽ. ZAGREB GOD. 21 (2012)

BR. $3(117)$

STR. $753-769$

ZEVNIK, L.:

EXPRESSION THROUGH... ture'. Campbell is convinced that in relation to craft there are 'two contrasting modes of production, so there are also two different modes of consumption' (Campbell, 2005, 39). The difference between craft and non-craft (industrial) production is not only seen at the level of actual production but also has 'two fundamentally contrasting ways in which human beings relate to the object world, ways that are diametrically opposed in their effects on those involved' (Campbell, 2005, 39). In this sense, 'while craftwork is seen as humane and liberating, enabling individuals to engage in authentic, expressive and creative activity, factory based and automated machine production is considered to have the opposite effect' (Campbell, $2005,39)$. Campbell warns that this dichotomy has frequently been simply carried over into the dimension of consumption in the sense that the consumption of craft objects is by itself considered as 'healthy educated discernment and good taste', as opposed to the alienating consumption of mass-manufactured goods (Campbell, 2005). Instead, he suggests that the two different modes of consumption do not simply correspond to the consumption of different kinds of goods but rather to the contrasting ways of relating to commodities:

Just as craft production is significant less for how the good is actually manufactured than for the opportunity it offers for human self-expression and creativity, so too is craft consumption important because of the opportunity it presents for the manifestation of similar valued human qualities (Campbell, 2005, 39).

While conceptualising the craft consumer, Campbell emphasises two meanings of the word craft: 'to make or fashion with skill, especially by hand', including activities like weaving, hand block printing, embroidery, silversmithing, jewellery making, bookbinding, furniture making and as 'made and designed by the same person' (Hanks, Harrod in Campbell, $2005,27)$, thus defining craft consumption as 'consumption activity in which the product concerned is essentially both 'made and designed by the same person' and 'to which the consumer typically brings skill, knowledge, judgement and passion while being motivated by a desire for self-expression' (Campbell, 2005, 23). Even though Campbell believes they seem very similar, it is inappropriate to simply associate craft consumption with customisation and personalisation (Campbell, 2005, 31). Craft consumers both design and make the product that they themselves consume but that does not necessarily mean that they produce them from scratch. The creation of new 'ensemble-style products' is also considered by Campbell as a typical form of contemporary craft consumption. Ensemble- 
DRUŠ. ISTRAŽ. ZAGREB GOD. 21 (2012), BR. $3(117)$

STR. $753-769$

ZEVNIK, L.: EXPRESSION THROUGH... -style products are created when an individual 'takes any number of mass-produced products and employs these as the raw materials for the creation of a new product, one that is typically intended for self-consumption' (Campbell, 2005, 28). Even though it is possible to buy a finished or off-the-shelf product or, alternatively, to pay experts who will design and manufacture it, typical craft consumers are 'rejecting these options and choosing instead to craft such products for themselves (Campbell, 2005, 33).

\section{COOKING AS A CRAFT AND LEISURE ACTIVITY}

The most widespread mode of the craft consumption of food is cooking and the preparation of food. Claiming that craft consumption is also the creation of new 'ensemble-style products', Campbell $(2005,34)$ believes that cooking is a good example of craft consumption:

\begin{abstract}
After all, the end product is made or fashioned with skill and by hand and even if the basic design may be taken from elsewhere (i.e. a recipe book), some improvisation frequently occurs. It is also an instance wherein skill and knowledge may enter into the choice of the raw materials (i. e. ingredients) and where there is ample room for creativity. At the same time, there exists an easy and readily available alternative consumption strategy, one that avoids the craft route, given that there are both a wide range of ready meals on the market as well as innumerable restaurants and takeaway outlets.
\end{abstract}

Even though we completely agree with Campbell on the above points, we believe that, without it shifting from labour to leisure, cooking would have lost important distinctive features of craft consumption: 'that it has a crucial autotelic or aesthetic dimension and, as, such, has 'a fundamental resemblance to play' and that besides bringing skill, knowledge and judgment, it also enables individuals to 'bring love and passion to their consumption activity' (Campbell, 2005, 27, 34). If we were to simply accept Campbell's arguments for the craft consumption of food, this would mean we would have to consider all kinds of domestic cookery as the craft consumption of food. With domestic cookery, food has - to some extent at least - always been 'fashioned with skill and by hand', there has always been an opportunity to put some 'skill and knowledge into the choice of raw materials', there have almost always been some other alternative consumption strategies and there has always been space for creativity in the kitchen, but this never necessarily implied that cooking was perceived as a leisure activity and a pleasure in itself to the extent 
DRUŠ. ISTRAŽ. ZAGREB

BR. 3 (117),

STR. 753-769

ZEVNIK, L. GOD. 21 (2012),

EXPRESSION THROUGH...

plains, 'food making is often not an everyday activity, but a special leisure activity'. And it is mostly this recent transformation of food culture that we believe ought to be associated with the craft consumption of food. Since 'for most people who deal with the task of preparing meals each day, either for families or as part of paid work, cooking is less an overtly aesthetic or intellectual experience than a banal chore' (Lupton, $1996,146)$, it can only with difficulty be considered as craft consumption. While everyday domestic cooking is chiefly motivated by a clear external goal, such as caring for others, the motivation for the craft consumption of food principally comes from seeking enjoyable experiences of cooking itself. Cooking is not only a means for achieving something (although enjoying food is also an important part of the craft consumption of food) but a pleasure and a passion in its own right. In addition, we think that the application of the notion of the craft consumption to food culture can also provide us with a better understanding and a more profound theoretical account of cooking as a leisure activity. In this sense, cooking is a leisure activity insomuch it is also a craft activity. At the same time, cooking can only be regarded as craft consumption in a pure sense if the individual also perceives it as a leisure/fun activity. This implies that important motives and features of the craft consumption of food cannot be separated from the social, cultural, economic and individual processes whose results have led some people to start perceiving and using cooking as a leisure activity. We believe that, alongside the motives and required conditions for the craft consumption of food, it is also these processes that have to be explained in order to do both: further apply the concept of the craft consumption to contemporary food culture and to better understand cooking as a leisure activity.

\section{THE CRAFT CONSUMPTION OF FOOD AS A STRATEGY OF DISTINCTION?}

From the perspective of Pierre Bourdieu, the shift from cooking as labour to cooking as leisure can be associated with the rise of the new middle classes, especially the new petite bourgeoisie, which in order to distinguish themselves from the old bourgeoisie and the working classes adopted 'a morality of pleasure as a duty' (Bourdieu, 1984, 367). 'The fear of not getting enough pleasure' is 'combined with a search for self-expression' (Bourdieu, 1984, 367), which in the field of food culture manifests as food-related leisure and craft activities: ${ }^{3}$

In contemporary western societies there is a gourmet culture among the economically privileged, in which 'artistic', 
DRUŠ. ISTRAŽ. ZAGREB

GOD. 21 (2012),

BR. $3(117)$

STR. $753-769$

ZEVNIK, L.:

EXPRESSION THROUGH... dining out at expensive and fashionable restaurants, and preparing special meals at home. The preparation and consumption of the meal therefore became a source of entertainment, of enhanced sensory and social enjoyment, pleasure rather than work (Lupton, 1996, 145).

Craft consumption enables classes who consider mass consumption as banal and superficial to engage in consumer culture with their own distinctive cultural values of 'taste, beauty, authenticity and personal expressiveness' (Campbell, 2005, 38). In this sense, the craft consumption (of food) can be seen as serving the new middle classes to mould the postmodern consumer society in a way which perpetuates their sense of class and cultural superiority. On the other hand, Warde's research into food tastes in the UK, even though it also confirms the persistence of class differences in food consumption, shows that few people actually use their food practices as strategies of distinction. Instead, Warde (1997, 155 in Ashley et al., 2004, 70) argues: 'consumption is now best characterized as undistinguished difference, a condition brought about by an obsession on the part of consumers with variety which matches the capacity of industry to provide mildly differentiated products in considerable volume.' Moreover, besides seeing craft consumption as possibly being motivated by a quest for distinction, Campbell (2005) provides us with another set of reasons and motives why especially the middle classes may have adopted craft consumption. He argues that many middle-class and professional people in recent years have experienced deprofessionalisation, increased bureaucratisation, external monitoring and formal performance assessments, yet they have still maintained an above-average income and a significant amount of cultural capital. According to Campbell $(2005,37,38)$, these are also the groups of people that have most enthusiastically embraced craft consumption. Craft consumption enables them to engage in the creative expressive activities they have lost due to rationalising interventions in the professional sphere. Their jobs no longer offer them a clear sense of identity ${ }^{4}$ and profound personal satisfaction and they thus have to seek them in the private sphere. Craft consumption can be seen as an appealing possibility for the middle class to balance out the economic alienating pressures imposed on them because it can offer personal pleasure and fun in creative (self)-expression and active quality leisure time as opposed to more instrumentalised and technicised labour time and passive mass consumption (Campbell, 2005). Craft consumers are usually 'more concerned than most about the possible "alienating" and homogenizing effects of mass consumption' (Campbell 2005, 36) and consequently might see this mode of consuming as an 
DRUŠ. ISTRAŽ. ZAGREB GOD. 21 (2012),

BR. $3(117)$

STR. 753-769

ZEVNIK, L.:

EXPRESSION THROUGH... alternative strategy to counter such economic pressures 'as more and more aspects of modern life become subject to this economic imperative, so more and more individuals might come to experience the need to escape from, or even counteract, this process' (Campbell, 2005, 36). In the world of extensive and progressive commodification, craft consuming enables individuals to 'make things special', 'singularly meaningful' or 'beyond price' without 'turning one's back on commercial society or by refusing to be involved in the world of goods' (Campbell, 2005, 37). Thus, people rather 'embrace the world of commodities and use one's own cultural and personal resources to transform these (goods) into 'singularities' (Campbell, 2005, 37).

Another important aspect of the abovementioned rationalising interventions in the professional sphere is time. Most of the time, the fast pace of modern life and the imperative of economic efficacy do not enable people to dedicate enough time and care to what they eat. Due to a lack of time or money they have to consume fast food, takeaway food or food in cafeterias. Even if they go to a restaurant during working hours, they usually have to eat in a hurry or the meal conversation is dedicated to business matters. Consuming food is reduced to providing fuel for the body that has to work, or to a work environment like business lunches. Some people get fed up with such food and the ways it is consumed and try to balance this by paying special attention to what they eat and how they prepare and consume food in their free time. These reactions can be seen as one of the 'practices of slow living' whereby, according to Parkins $(2004,364)$, this 'slowness' is 'constructed as a deliberate subversion of the dominance of speed'. For Parkins (2004, 364), 'living slowly' means 'engaging in mindful rather than mindless practices which make us consider the pleasure or at least the purpose of each task to which we give our time'. The concept of slowness not only helps us understand the important array of possible motives for the craft consumption of food, but it can also be seen as one of the important elements and motives for craft consumption in general.

Considering Cambell's discussion of deprofessionalisation and commodification and that Warde's work suggests 'that while there are significant class differences in food consumption, the meaning of these differences cannot be simply equated with a quest for distinction' (Ward in Ashley et al., 2004,70 ), it seems that in the discussion on the craft consumption of food, it is more suitable to regard class not so much as being connected with craft consumption in terms of strategies of distinction but more in terms of providing the required dispositions and the material, temporal and cultural conditions for the craft consumption of food and thus enabling certain 
DRUŠ. ISTRAŽ. ZAGREB GOD. 21 (2012), BR. 3 (117),

STR. $753-769$

ZEVNIK, L.: EXPRESSION THROUGH... people to experience cooking as both a leisure and craft activity to a greater extent than others. This was proven by Lupton's research in Australia that showed that all of the participants in an interview study who expressed a highly aestheticized approach to food 'were economically privileged and employed in professional occupations' (Lupton, 1996, 145). Obviously, for cooking to be used as a craft and leisure activity, enough (leisure) time is required along with certain economic/material conditions like a kitchen, cookware and various cooking ingredients etc. Besides a distance from economic and temporal constraints, the craft consumption of food also requires a certain amount of cultural capital that enables the consumer 'to envisage commodities as raw materials that can be employed in the construction of composite "aesthetic entities" and also to know what principles and values are relevant to the achievement of these larger constructions' (Campbell, $2005,36)$. On the other hand, although certain ingredients and special cookware used in the preparation of exquisite meals that form an important part of the new culinary aesthetics of the (new) middle and higher classes are quite costly, Campbell $(2005,36)$ believes that this does not mean that 'members of the poorer ranks of modern societies (poor, that is, in either the conventional and/or cultural sense of the term) are necessarily excluded altogether from undertaking craft consumption, for not all activities of this kind require considerable capital or expenditure'. Indeed, having economic limitations requires even more creativity and improvisation in the kitchen and hence being economically less well off and not being able to cook with exotic and expensive ingredients and cookware does not necessarily mean that one cannot engage in food craft activities and take pleasure in cooking. In addition, Campbell argues that not 'all sections of the less well off' are without sufficient leisure time and that 'the requisite cultural capital is often relatively easy to obtain' (Campbell, 2005, 36), often via the increasing number of cookery books, cooking instructions in various magazines, on the Internet and in cookery TV programming. The latter is an 'especially important media for the transmission' of the cultural capital required for craft consumption because 'aspiring practitioners need to be shown rather than told how to do it' (Campbell, 2005, 40).

Jamie Oliver's first TV show The Naked Chef5 and its sequels are a good example of this type of cookery programming that offers instructions on how to craft consume food and 'through a discourse of accessibility and achievability' also clearly represents craft consumption of food (Moseley, 2001, 39). If we recall Campbell's description of craft consumption of food, we can find Jamie Oliver (as well as other similar celebrity chefs) a typical craft consumer of food. Jamie Oliver 
DRUŠ. ISTRAŽ. ZAGREB GOD. 21 (2012),

BR. $3(117)$

STR. 753-769

ZEVNIK, L.:

EXPRESSION THROUGH... is one of the most famous celebrity chefs. His TV shows are aired and his books have been published in more than 10 countries. As a result of their popularity, Jamie's shows are probably some of the most widespread and typical media representations of the craft consumption (of food). In the Naked Chef, Jamie shows a lot of skill and knowledge while choosing and buying his cooking ingredients. He does not shop in a supermarket; rather he visits small highly specialised shops, delis and various markets enjoying the personal service and advice of the proprietors. Even for those ingredients where we are not shown how he buys them, when he pulls them out from a cupboard or fridge, he almost always explains their properties and justifies why and how he is using them. At every stage of the cooking process he demonstrates both hand skills as well as profound knowledge of the ingredients and the relations between them and the recipes. These skills and knowledge enable him to improvise with recipes and cooking procedures in a creative way, constantly inventing new recipes and at the same time offering detailed instructions on how to craft consume food. Even when he prepares classical dishes, he almost always adds a certain new creative and improvised dimension to them. He does not employ many special kitchen appliances or tools. Instead, he improvises with his hands (like squeezing a halved lemon by hand instead of using a lemon squeezer) or other more basic kitchen tools (like using a chef's knife to crush garlic). It seems like he is putting a lot of pathos into his cooking, making expressive hand movements and gesticulations giving the impression he is an artist really enjoying what he is doing. Jamie Oliver's shows also reveal another important motive for the craft consumption of food: socialising. Jamie puts a lot of emphasis on the social aspect of dining. He cooks at home, invites people over and shares his food with his friends, family etc. Cooking is presented as a social event that reaches far beyond the boundaries of the kitchen or the kitchen itself is shown as a venue for socialising. In Jamie's words, 'It's not just food, it's socializing, it's having a laugh'.

Since Lupton's $(1996,145)$ research found that most of the participants in her study who expressed a 'highly aestheticized approach to food' were men, we will now turn to Hollows' study of Jamie Oliver in which she draws on wider feminist appropriations of Bourdieu to suggest that the ability to experience cooking as leisure depends not only on class but also on gender. While our former discussion provided plausible arguments against simply seeing the craft consumption of food as a strategy of distinction in terms of class, Hollows' (2003) study provides much more convincing arguments for the craft 
DRUŠ. ISTRAŽ. ZAGREB GOD. 21 (2012), BR. $3(117)$

STR. $753-769$

ZEVNIK, L.: EXPRESSION THROUGH... consumption of food to be associated with a gendered quest for distinction. ${ }^{6}$ Hollows $(2003,243)$ argues that 'Jamie's culinary masculinity, in which domestic cooking is experienced as a form of creative leisure, is also a product of a distance from domestic obligation and labour (and the accompanying experience of time poverty and the need for constant temporal-management) associated with women's position in the sexual division of labour'. Hollows' conclusion 'that the competences and dispositions which the new petit-bourgeoisie have been seen to bring to "the art of everyday life" may themselves be more open to men than women and, in particular, when they concern aspects of domestic life' (Hollows, 2003, 243), implies that craft activities in domestic food preparation can also be seen as being more open to men than women. The fact that, apart from some exceptions, the majority of the worlds leading (celebrity) chefs are men additionally supports this thesis. In this sense, men try to establish their way of cooking as leisure and craft activities superior to women's banal cooking activities perceived as a duty.

\section{DOMESTIC FOOD GROWING AS THE CRAFT CONSUMPTION OF FOOD}

We believe there is sufficient evidence to claim that the craft consumption of food is not only limited to cooking and the preparation of food but also to certain forms of contemporary domestic food growing. Given that for Campbell $(2005,2,12)$ gardening is one of the main forms of craft consumption, growing food at home on a smaller scale can also be regarded as a craft activity. A possible objection to this broadening of the concept of the craft consumption of food might be that these activities would no longer be classified as consumption but in fact amount to the production of food. Campbell addressed similar doubts in the case of food preparation, which he believes 'is a production activity as much as (or, indeed, rather than) a consumption one. However, when not undertaken as paid labour and by those who also intend to eat the end product, such a distinction is difficult to make' (Campbell 2005, 33). Following Campbell's argumentation, it is obvious that going just outside your house to your vegetable garden and picking a fresh lettuce is a process of consuming just as much as buying it in a supermarket is. In addition to Campbell's argument that can also be well applied to food growing, it is possible to identify even more features and motives that, in the case of certain modes of contemporary domestic food growing, blur the difference between consumption and production and at the same time suggest that these modes are significantly different from traditional domestic food growing. We believe that mainly these modes of domestic food grow- 
DRUŠ. ISTRAŽ. ZAGREB GOD. 21 (2012)

BR. $3(117)$

STR. 753-769

ZEVNIK, L.:

EXPRESSION THROUGH... ing, which are becoming ever more widespread in contemporary Western societies, should be associated with the craft consumption of food. With these craft activities, smaller quantities of food are produced and consumed by the individual himself and a few of the people close to him (and are not intended for sale). This is most commonly done in a(n) (allotment) garden or even in pots on a balcony or inside a house by hand or with the help of simple tools or machines. These activities are not a necessity for the individual since, with the hyper productive food industry supplying the contemporary food market, there is in many ways a more convenient alternative consumption strategy. Home-grown crops only represent an addition to the food acquired in shops, various food markets and (super)markets. Hence, these craft activities are typical leisure activities carried out in one's free time and are, even though they can cut food expenses, far from being the main means of one's livelihood. As such, growing food at home is usually not undertaken because these activities would be essential for survival or only from a pragmatic economical aspect, as was the case of traditional domestic food growing in the past, but is instead driven by certain political, hedonistic and emotional (self)-expressions and anxieties. It is also revealing that these craft activities are usually undertaken by people who never previously grew their own food. Moreover, in many cases they do so in urban places that before were seldom intended for this purpose and are in fact not optimal for food agriculture. The titles of the two latest popular books on food growing also demonstrate this point. Both Flores' Food not Lawns and Haeg's Attack on the Front Lawn suggest that crops should be planted in places where previously and traditionally they were not.

There appears to be quite some evidence that this type of domestic food growing is becoming more and more popular in contemporary societies in Europe and the USA. In the USA, a certain revival of domestic food growing was initiated especially by Flores' book. This probably happened not so much because the book proved revolutionary in the sense of offering innovative (permaculture) instructions on how to grow food, but more because it was 'revolutionary' in a political sense. Flores (2006) introduced a strong political/activist approach to food growing by claiming that: 'practicing ecological living is a deeply subversive act'. For Flores, growing food in the place where you live is the most important way to become a food activist in the community. Her instructions on how to grow food are placed in a wider context that emphasise the close connection between the micro politics of domestic food growing and the macro politics of consumption and sustainability. Numerous offshoot Food Not Lawns groups are currently active 
DRUŠ. ISTRAŽ. ZAGREB GOD. 21 (2012), BR. $3(117)$

STR. $753-769$

ZEVNIK, L.: EXPRESSION THROUGH... in the USA that emerged and were inspired by the original Food Not Lawns grassroots gardening project in Eugene, Oregon, USA (Cascadia Food Not Loans, 2008). Fritz Haeg, the author of the latest book with a similar vision: Edible estates: Attack on the Front Lawn (2008) reports great interest in his ideas (Cnn.com, 2007). According to Haeg (2008) 'Edible Estates is an on-going series of projects to replace the front lawn with edible garden landscapes responsive to culture, climate, context and people'. Similar to Flores' idea, Haegs's (2008) vision also includes both 'revolutionary' rhetoric and the 'think globally act locally' food production logic. Interest in Flores' and Haeg's projects clearly illustrates how this mode of the craft consumption of food can be motivated not only by economic and production motives but also by political and environmental passions. Food growing is seen as a political statement representing an important expression of a 'greener way of life'.

The connection between home food growing and a greener way of life aimed at protecting the environment and the health of individuals becomes even clearer when we also consider anxieties about the industrial production of food that can reflect either health, ethical or quality concerns. A large number of people in contemporary Western societies think that modern industrial food production harms the environment and/or produces food which is unsafe, unhealthy or does not achieve adequate quality because it is genetically modified or due to the extensive use of artificial herbicides and fertilisers, synthetic additives and other industrial procedures applied in its production. Given that these anxieties are further exacerbated by frequent media panics and food scares, it makes sense that some people decide to grow their own food. In order to better understand such food anxieties, they have to be put in a wider context of the 'risk society'. According to Beck $(1992,21)$, the risk society is a new social condition caused by (reflexive) modernisation and globalization where 'risk may be defined as a systematic way of dealing with hazards and insecurities induced and introduced by modernization itself'. For our discussion, two of Beck's reasons for the risk society are especially important: the fact that compared to the pre-modern era, modern risks are largely invisible and that they have their basis in industrial overproduction (Beck, 1992, 21). In the case of food production, these two reasons are closely interconnected. The majority of people are today aware that most of the food they consume is industrially produced. At the same time, they are unable to actually trace these processes, which thus appear invisible to them. In addition, many of them do not trust the institutions that are supposed to monitor food quality and food safety. According to Goode et al. 
DRUŠ. ISTRAŽ. ZAGREB GOD. 21 (2012),

BR. 3 (117),

STR. 753-769

ZEVNIK, L.:

EXPRESSION THROUGH...
(1995), $60 \%$ of the people in Great Britain do not trust the food industry, 59\% do not trust the government and $44 \%$ do not trust farmers to sufficiently care about food safety.

In addition to risk reduction, possible money savings and political activism, domestic food growing can also be motivated by the personal satisfaction that comes from picking fresh, high quality crops right from one's own garden or windowsill and/or by the joy, passion and relaxation experienced in the actual gardening process. These hedonistic motives are vividly represented in Jamie Oliver's book Jamie at Home ${ }^{7}$ and his latest TV show with the same title. In his last book/TV show, he turned to food growing, and similarly as in his other shows, 'through a discourse of accessibility and achievability' (Moseley, 2001,39) he offers an apolitical and more hedonistic interpretation of domestic food growing: 'So Jamie at Home is all about getting down and dirty with nature, growing and cooking your very own produce' (Oliver, 2008).

Jamie sees growing food as closely connected with cooking and cares for and picks vegetables and fruits in his garden with the same passion as he later expresses in cooking. In every show he focuses on a certain fruit, vegetable or vegetable family. While walking around the garden he explains how he and his gardener grow them and puts special emphasis on how they can be best used and prepared in the kitchen. Jamie Oliver (2008) sees growing food as a direct inspiration for cooking: 'something began to inspire me very quickly...my vegetable patch! I came to realize last year that it's not always about looking out at the wider world for inspiration'.

Jamie emphasises creativity and improvisation that are important features of the craft consumption of both food growing and cooking. He explains that his improvisation is due to a lack of proper kitchen tools. His kitchen is simple and so is his cookware. He uses older pots, bowls, knives and cutting boards. For example, he cuts onions using a knife too large for the job, explaining that that is the only one he has at hand. Jamie prepares simpler recipes outside, right in the garden. The main thread of the Jamie at Home series is a retro style, worn out notebook, which includes handwritten and hand drawn instructions for growing and cooking food and visually connects and helps to make transitions between scenes in the show. This visual effect gives the impression the notebook is composed right there on the spot while gardening and cooking, which also explains its worn out look. The notebook is symbolically an important metaphor for craft consumption. It fills the activities of cooking and gardening that might be seen as banal everyday chores with some additional symbolical meaning. The carefully composed notes imply these activities are undertaken with great care, skill, devotion and attention. 
DRUŠ. ISTRAŽ. ZAGREB

BR. 3 (117),

STR. 753-769

ZEVNIK, L.:

EXPRESSION THROUGH..
GOD. 21 (2012),

Even though the social aspect of food culture in the $J a-$ mie at Home series is almost completely left out, some other evidence shows that food growing can also have a significant socialising aspect. Haeg (2008), for example, promotes food growing as a way to socialise: 'Food grown in our front yards will connect us to the seasons, the organic cycles of the earth, and our neighbors'. Also Cnn.com (2007) reports that some enthusiastic urban vegetable and fruit growers have started to realise that spending time on their front-yard gardens can be an opportunity to socialise with their neighbours, giving them their first-ever excuse to speak to them.

\section{CONCLUSION}

We have suggested that there are two major modes of craft consumption of food in contemporary society and found that the conditions, reasons and motives for both of them are varied and complex. We agree with Campbell $(2005,24)$ that the craft consumption of food is motivated 'principally out of desire to engage in creative acts of self-expression'. Of course, there are also other factors that require attention. In the case of cooking and the preparation of food, class issues undoubtedly play an important role. While, according to Campbell (2005, $37,38)$, especially the middle classes have embraced craft consumption, we have shown that it is impossible to simply associate it with their quest for distinction. It is probably more likely that class is significant for providing the required conditions for craft consumption and that it is more possible that the craft consumption of food is perceived as a quest for distinction only in terms of gender. Namely, that cooking and the preparation of food as craft and leisure activities are more open to men than women. Regarding class issues, it seems more plausible to suggest that the middle classes are more keen on craft consumption as it enables them to counter rationalising interventions in the professional sphere that, through deprofessionalisation, limit their expressive potential. This is even more likely since they maintain a significant amount of economic and cultural capital. On the other hand, we suggested that being economically less well off does not necessarily exclude people from engaging in craft consumption of food.

The aim of our analysis was not to pinpoint which factors of craft consumption of food are predominant for certain people or groups of people. Indeed, such an undertaking would require extensive additional qualitative and quantitative research. What we can conclude based on our exploration of possible motives and reasons for craft consumption is that there are new meanings that people attribute to food and cooking that seem to differ significantly from their traditional food 
DRUŠ. ISTRAŽ. ZAGREB GOD. 21 (2012),

BR. $3(117)$

STR. 753-769

ZEVNIK, L.:

EXPRESSION THROUGH.. practices. While cooking, food preparation and domestic food growing are some of the oldest human activities, they have acquired new creative, expressive, symbolic, social and economical dimensions in the contemporary consumer culture that call for a new theoretical perspective. In this sense, the theory of craft consumption and its application to food culture has proved especially useful. Last but not least, the application of the notion of craft consumption to food culture also enables us to better understand cooking and domestic food growing as one of the leisure activities in contemporary society.

\section{NOTES}

\section{REFERENCES} New York, Penguin.

2 See Haeg, F. (2008), Edible Estates: Attack on the Front Lawn, Los Angeles, Metropolis Books.

3 One of the most influential expressions of food related leisure is certainly the Slow Food movement (for more on Slow Food see Jones et al., 2003).

4 For more on identity issues see Toplak et al. (2011).

5 See Oliver, J. (1999), The Naked Chef, London, Michael Joseph.

${ }^{6}$ For a more in-depth study about general issues regarding gender, food and cooking see Charles and Kerr (1988).

7 See Oliver, J. (2007), Jamie at Home, London, Michael Joseph.

Ashley, B., Hollows, J., Jones, S. and Taylor, B. (2004), Food and Cultural Studies, London, New York, Routledge.

Beck, U. (1992), Risk Society: Towards a New Modernity, London, Sage. Bordieu, P. (1984), Distinction: A Social Critique of the Judgement of Taste, Cambridge, Harvard University Press.

Campbell, C. (2005), The Craft Consumer. Journal of Consumer Culture, 5 (1): 23-42. doi:10.1177/1469540505049843

Cascadia Food Not Lawns (2008), Others Food Not Lawns Groups [online]. Available at http://www.foodnotlawns.com/ [Accessed 5 May 2008].

Charles, N. and Kerr, M. (1988), Women, Food and Families: Power, Status, Love, Anger, Manchester, Manchester University Press.

Cnn.com (2007), Growing Front-Yard Food Can Rile Neighbors [online]. Available at http://edition.cnn.com/2007/LIVING/wayoflife/07/24/ veggie.patch.ap/index.html/ [Accessed 5 May 2008] (in 2012 available at http://curezone.com/forums/am.asp?i=932038)

Flandrin, J. and Montanari, M. (2000), Food: A Culinary History, New York, Penguin.

Flores, H. (2006), Food Not Lawns: How to Turn Your Yard into a Garden And Your Neighborhood into a Community, White River, Chelsea Green. 
DRUŠ. ISTRAŽ. ZAGREB GOD. 21 (2012), BR. $3(117)$

STR. $753-769$

ZEVNIK, L.: EXPRESSION THROUGH...
Goode, J., Beardsworth, A., Haslam, C., Keil, T. and Sherratt, E. (1995), Dietary Dilemmas: Nutritional Concerns of the 1990s. British Food Journal, 97 (11): 1-13.

Haeg, F. (2008), Edible Estates: Attack on the Front Lawn. Available at http://www.fritzhaeg.com/wikidiary/ [Accessed 5 May 2008].

Hollows, J. (2003), Oliver's Twist: Leisure, Labour and Domestic Masculinity in The Naked Chef. International Journal of Cultural Studies, 6 (2): 229-248. doi:10.1177/13678779030062005

Jones, P., Shears, P., Hillier, D., Comfort, D. and Lowell, J. (2003), Return to Traditional Values? A Case Study of Slow Food. British Food Journal, 105 (4/5): 297-304.

Lupton, D. (1996), Food, the Body and the Self, London, Thousand Oaks, New Delhi, Sage.

Moseley, R. (2001), Real Lads Do Cook ... But Some Things are Still Hard to Talk About: The Gendering of 8-9. European Journal of Cultural Studies, 4 (1): 32-39.

Oliver, J. (1999), The Naked Chef, London, Michael Joseph.

Oliver, J. (2007), Jamie at Home, London, Michael Joseph.

Oliver, J. (2008), Jamie at Home [online]. Available at http://www. jamieoliver.com/jamieathome/introduction/ [Accessed 5 May 2008].

Parkins, W. (2004), Out of Time: Fast Subjects and Slow Living. Time E Society, 13 (2-3): 363-382. doi:10.1177/0961463X04045662

Toplak, C., Velikonja, M., Pikalo, J., Stanković, P., Šabec, K. and Komel, M. (2011), A Europe of Homelands or Homeland Europe: (European) Identity Issues. Dve domovini, 33: 23-35.

\section{Izražavanje uzgojem i kuhanjem hrane: "kreativna" potrošnja hrane}

Luka ZEVNIK

Fakultet društvenih znanosti, Ljubljana

Ovaj rad primienjuje Campbellovu teoriju "kreativne" potrošnje (2005.) na suvremenu kulturu hrane. U njemu se tvrdi da se osim kuhanja i pripreme hrane i neki oblici vlastita uzgoja hrane mogu smatrati "kreativnom" potrošnjom hrane. Pokušavaju se zapravo utvrditi uvjeti i mogući motivi za obje vrste "kreativne" potrošnje hrane koji mogu rasvijetliti društvene, simboličke, izražajne i ekonomske posebnosti novih oblika bavljenja hranom i pomoći opisati kako se oni razlikuju od svojih tradicionalnih obrazaca. Naposljetku, ali ne i manje važno, u radu se tvrdi da nam u onoj mieri u kojoj su kreativne aktivnosti po definiciiji uvijek aktivnosti slobodna vremena, i primiena pojma "kreativne" potrošnje na kulturu hrane također može pružiti bolje razumijevanje kuhanja i vlastita uzgoja hrane kao aktivnosti slobodna vremena.

Ključne riječi: kultura hrane, "kreativni" potrošač, "kreativna" potrošnja hrane, (samo)izražavanje, kuhanje, domaći uzgoj hrane 